\title{
DETECCIÓN SEROLÓGICA DE Ehrlichia canis y Ehrlichia chaffeensis EN PERSONALDE CLÍNICAS VETERINARIAS EN LIMA METROPOLITANA
}

\author{
Serologic Detection of EHrLichia Canis AND EHRLichia CHAFFENSIS IN STAfF OF \\ Veterinary Clinics in Lima
}

\author{
Analí Paulino R. ${ }^{1}$, Olga Li E. ${ }^{1,4}$, Luis Hoyos S. ${ }^{1}$, Francisco Suárez A. ${ }^{2}$, Diego Díaz C. ${ }^{3}$
}

\section{Resumen}

El objetivo del presente estudio fue determinar la presencia de seropositividad a Ehrlichia canis y Ehrlichia chaffeensis en personal de clínicas veterinarias y en personas en contacto con canes con Ehrlichiosis canina, utilizando la prueba de inmunofluorescencia indirecta. Se emplearon 90 muestras de suero de 55 varones y 35 mujeres. Se encontró $23.3 \%$ de seropositividad a E. canis y $20.0 \%$ a E. chaffeensis, sin asociación estadística por efecto de género.

Palabras clave: Ehrlichia canis, Ehrlichia chaffeensis, inmunofluorescencia indirecta, humanos

\section{Abstract}

The aim of the present study was to detect seropositivity against Ehrlichia canis and Ehrlichia chaffeensis in staff of veterinary clinics and in persons that had contact with dogs affected by canine ehrlichosis using the indirect immunofluorescence test. Ninety serum samples were used, 55 men and 35 women. Results indicated $23.3 \%$ of seropositivity to $E$. canis and $20.0 \%$ to $E$. chaffeensis, without statistical differences due to gender.

Key words: Ehrlichia canis, Ehrlichia chaffeensis, indirect inmunofluorescence, humans

\footnotetext{
${ }^{1}$ Laboratorio de Patología Clínica y Biología Molecular, ${ }^{2}$ Laboratorio de Medicina Veterinaria Preventiva, ${ }^{3}$ Clínica de Animales Menores, Facultad de Medicina Veterinaria, Universidad Nacional Mayor de San Marcos, Lima

${ }^{4}$ E-mail: olgalie@hotmail.com
} 
Existen muchas enfermedades transmitidas por garrapatas, tanto a animales como a humanos, y dentro de ellas se encuentran las producidas por el género Ehrlichia (Breitschwerdt et al., 1998). La ehrlichiosis se considera como una enfermedad zoonótica emergente, reportándose múltiples casos alrededor del mundo (Paddock y Childs, 2003). Existen evidencias serológicas de ehrlichiosis humana en Argentina (Ripoll et al., 1999), Chile (López et al., 2003) y Venezuela (Arraga, 1994; Arraga et al., 1996).

En el departamento de Ancash, Perú, se ha reportado $9.2 \%$ de seropositividad utilizando la técnica de inmunofluorescencia indirecta (IFI) (Anaya et al., 2009); así mismo, Moro et al. (2009) en un estudio sobre $E$. chaffeensis, causante de la ehrlichiosis monocítica humana, utilizando la misma técnica, hallaron una seropositividad de 3, 23 y $25 \%$ en la costa (Lima), sierra (Cusco) y selva (Iquitos), respectivamente.

En relación a ehrlichiosis canina, se reportó una seroprevalencia de $16.5 \%$ en Lima Metropolitana (Adrianzen et al., 2003) y de $76 \%$ en Sullana, Piura (San Miguel, 2006). Esta enfermedad, dadas las condiciones medioambientales, tiene una alta probabilidad epidemiológica en la zona, donde la presencia de perros con E. canis implica que puedan actuar como reservorio de agentes de Ehrlichiosis humana, tal y como sucede en Venezuela (Unver et al., 2001). La posibilidad que los perros puedan facilitar la transmisión de esta bacteria al humano incrementaría su importancia zoonótica (Vinasco et al., 2007).

El objetivo del presente estudio fue detectar la presencia de anticuerpos contra $E$. canis y E. chaffeensis en personas que realizan actividades veterinarias y en aquellas que tienen contacto con cánidos con ehrlichiosis, a fin de poder realizar, en el futuro mediato, estudios zoosanitarios referentes a medidas de prevención y control.

\section{Participantes del Estudio}

En el estudio participaron 90 individuos procedentes de varios distritos de Lima Metropolitana, los cuales realizaban actividades veterinarias (médicos veterinarios, practicantes de Medicina Veterinaria, bañadores y personal de limpieza en clínicas veterinarias), así como individuos que habían tenido contacto con animales con Ehrlichiosis canina.

\section{Muestras y Análisis de Laboratorio}

Se colectaron $5 \mathrm{ml}$ de sangre periférica en tubo de ensayo sin anticoagulante a cada participante del estudio. El suero se obtuvo por centrifugación a $4000 \mathrm{rpm}$ por 10 minutos, separándose el suero en viales descartables $(2 \mathrm{ml})$ y se almacenó a $-20{ }^{\circ} \mathrm{C}$ hasta su procesamiento.

Los sueros fueron evaluados mediante Inmunofluorescencia Indirecta (IFI), utilizando placas para E. chaffeensis y para $E$. canis. Esta técnica corresponde al «estándar de oro» para Ehrlichiosis animal y humana, en el que los resultados fueron considerados como positivos o negativos utilizando la dilución (1:50) como punto de corte. Se utilizó un microscopio de epifluorescencia (Leica) para la lectura.

\section{Análisis Estadístico}

Se calculó la tasa de prevalencia de individuos positivos a $E$. canis y $E$. chaffeensis, incluyendo el intervalo de confianza del $95 \%$. Asimismo, se evaluó la asociación entre la seropositividad de la prueba y la variable género mediante la prueba de Chi Cuadrado.

\section{Resultados}

Se encontraron 21 casos seropositivos a $E$. canis $(23.3 \%)$ y 18 seropositivos a $E$. chaffeensis $(20.0 \%)$, sin encontrar diferen- 
Cuadro 1. Seropositividad a Ehrlichia canis en personas, según género, que laboran en clínicas veterinarias y en personas en contacto con canes con Ehrlichiosis (Lima, 2009)

\begin{tabular}{lcccc}
\hline \multirow{2}{*}{ Género } & $\mathrm{N}^{\mathrm{o}}$ de muestras & \multicolumn{2}{c}{ Seropositivos } & \multirow{2}{*}{$\mathrm{X}^{2}$} \\
\cline { 3 - 4 } & & $\mathrm{N} .^{\circ}$ & $\%$ & \\
\hline Varones & 55 & 12 & 21.8 & \\
Mujeres & 35 & 9 & 25.7 & \multirow{2}{*}{0.18} \\
\hline Total & 90 & 21 & 23.3 & \\
\hline
\end{tabular}

Cuadro 2. Seropositividad a Ehrlichia chaffe ensis en personas, según género, que laboran en clínicas veterinarias y en personas en contacto con canes con Ehrlichiosis (Lima, 2009)

\begin{tabular}{lcccc}
\hline \multirow{2}{*}{ Género } & $\mathrm{N}^{\mathbf{0}}$ de muestras & \multicolumn{2}{c}{ Seropositivos } & \multirow{2}{*}{$\mathrm{X}^{2}$} \\
\cline { 3 - 4 } & & $\mathrm{N} .^{\circ}$ & $\%$ & \\
\hline Varones & 55 & 10 & 18.2 & \\
Mujeres & 35 & 8 & 22.9 & \multirow{2}{*}{0.29} \\
\hline Total & 90 & 18 & 20.0 & \\
\hline
\end{tabular}

$\mathrm{p}<0.05$

cias significativas por género en ninguno de los dos patógenos (Cuadros 1 y 2).

\section{Discusión}

En el Perú, el diagnóstico de Ehrlichiosis se realiza principalmente en caninos (Ehrlichiosis canina), especialmente en épocas de calor debido al incremento del número de vectores transmisores de la enfermedad.

Los primeros casos de Ehrlichiosis humana en Venezuela fueron reportados en 1994 (E. chaffeensis, Ehrlichiosis Granulo- cítica Humana y E. platys) (Tamí et al., 1994; Arraga et al., 1996; Pérez et al., 1996); asimismo, en plaquetas de humanos se detectaron mórulas semejantes a las encontradas en caninos (Tamí et al., 1994; Tamí y Jordan, 2002). En 1996, también en Venezuela, fue aislado un agente ehrlichial semejante a $E$. canis en un hombre asintomático (Pérez et al., 1996). Más adelante, en el 2006, mediante PCR y utilizando el gen ARN $r 16 \mathrm{~S}$, se encontró $30 \%$ de positivos para $\mathrm{ADN}$ de $E$. canis en pacientes con sintomatología compatible a Ehrlichiosis, constituyendo el primer reporte de infección por E. canis en humanos (Pérez et al., 2006). 
El potencial zoonótico del agente causal de la Ehrlichiosis canina (E. canis) ha sido reportado en América Latina (Arraga, 1994; Tamí et al., 1994; Pérez et al., 1996), incluyendo el Perú (Anaya et al., 2009; Moro et al., 2009). El presente estudio es el primero que intenta evaluar casos de seropositividad en médicos veterinarios e individuos que hayan trabajado con animales con esta enfermedad.

Existe una marcada reacción cruzada entre E. canis y E. chaffeensis, debido a que comparten varios antígenos superficiales homólogos (Yu et al., 2000). Por lo tanto, la seropositividad hallada contra $E$. chaffeensis podría deberse a la reacción cruzada entre ambas. Para sustentar la sospecha de la presencia de este agente en el medio, se necesitaría la confirmación mediante la detección de seroconversión, detección de mórulas en células circulantes o ADN de $E$. chaffeensis en muestras sanguíneas (López et al., 2003). Además, es importante resaltar que se dispone de un reporte de Ehrlichiosis Granulocítica Canina en el 2005, a partir de un canino doméstico en el distrito de La Molina, Lima (Li et al., 2005).

Si bien ya se había encontrado seropositividad en individuos con sintomatología sugestiva a Ehrlichiosis humana en el departamento de Ancash (Anaya et al., 2009), así como un reporte que señala $13 \%(21 / 160)$ de seroprevalencia contra E. chaffeensis (Moro et al., 2009), el presente estudio encontró una seropositividad mayor, posiblemente debido a que los individuos participantes fueron médicos veterinarios y personas que trabajaban con animales con Ehrlichiosis canina.

Los resultados del presente estudio demuestran la exposición a microorganismos del género Ehrlichia spp en humanos en Lima Metropolitana. Este hallazgo abre las puertas para la investigación en un nuevo grupo de rickettsias que puedan estar involucradas en diversas patologías en humanos, y que no hayan sido consideradas debido a la falta de información.

\section{Conclusiones}

- Se demuestra la presencia de anticuerpos contra Ehrlichia chaffeensis y Ehrlichia canis en personal que labora en clínicas veterinarias en Lima Metropolitana o que ha tenido contacto con canes domésticos con Ehrlichiosis canina.

- No se encontró asociación entre género y seropositividad contra $E$. chaffeensis o E. canis.

\section{Literatura Citada}

1. Adrianzen J, Chávez A, Casas EC. 2003. Seroprevalencia de la dirofilariosis y ehrlichiosis canina en tres distritos de Lima. Rev Inv Vet, Perú 14(1): 43-48.

2. Anaya E, Morón C, Jaramillo K, Mendoza L, Román R. 2009. Evidencia serológica de ehrlichiosis humana en Ancash - Perú. Rev Perú Med Exp Salud Pública 26(1): 54-57.

3. Arraga C. 1994. Ehrlichiosis humana. Revisión. Invest Clín 35: 209-222.

4. Arraga C, Montero M, Bernardoni A, Anderson $R$, Parra $O .1996$. Ehrlichiosis humana: reporte del primer caso en Venezuela / Human ehrlichiosis: report of the first case in Venezuela. Invest Clin 37: 35-49.

5. Breitschwerdt EB, Hegarty $B C$, Hancock SI. 1998. Sequential evaluation of dogs naturally infected with Ehrlichia canis, Ehrlichia chaffeensis, Ehrlichia equi, Ehrlichia ewingii, or Bartonella vinsonii. J. Clin Microbiol 36:2645-2651.

6. Li O, Díaz del Olmo J, Fernández V, Hoyos L, Moro M. 2005. Primer reporte de ehrlichiosis granulocítica canina. I Congreso CANFELEX. LimaPerú.

7. López J, Rivera M, Concha J. 2003. Ehrlichiosis humana en Chile, evidencia serológica. Rev Med Chile 131: 67-70.

8. Moro P, Shah J, Li O, Gilman RH, Harris N, Moro M. 2009. Short report: serologic evidence of human ehrlichiosis 
in Peru. Am J Trop Med Hyg 80: 242244.

9. Paddock CD, Childs JE. 2003. Ehrlichia chaffeensis: a prototypical emerging pathogen. Clin Microbiol Rev 16: 37-64.

10. Perez M, Rikihisa Y, Wen B. 1996. Ehrlichia canis-like agent isolated from a man in Venezuela: antigenic and genetic characterization. J Clin Microbiol 34: 2133-2139.

11. Perez M, Boodor $M$, Zhang $C$, Xiong $Q$, Rikihisa Y. 2006. Human infection with Ehrlichia canis accompanied by clinical signs in Venezuela. Ann N Y Acad Sci. 1078: 110-117.

12. Ripoll CM, Remondegui CE, Ordonez $G$ Arazamendi R, Fusaro H, Hyman MJ. 1999. Evidence for rickettsial spotted fever and ehrlichial infections in subtropical territory of Jujuy, Argentina. Am J Trop Med Hyg 61: 350-354.

13. San Miguel SY. 2006. Prevalencia de Ehrlichia canis en caninos de la provincia de Sullana. Tesis de Médico Veterinario. Lima: Universidad Alas Peruanas. $51 \mathrm{p}$.
14. Tamí I, García F, Tamí M, Arcia R. 1994. Ehrlichiosis en animales y humanos en Venezuela. Act Cient Soc Venz Bioanal Espec 3: 19-24.

15. Tamí I, Jordan L. 2002. Identificación de mórulas de Ehrlichia en plaquetas de sangre humana en Venezuela. Antibióticos e Infección 10: 123-128.

16. Unver A, Perez M, Orellana N, Huang H, Rkihisa Y. 2001. Molecular and antigenic comparison of Ehrlichia canis isolates from dogs, ticks and a human in Venezuela. J Clin Microbiol 39: 27882793.

17. Vinasco J, Li O, Alvarado A, Diaz D, Hoyos L, Tabacchi L, Sirigireddy K, et al. 2007. Molecular evidence of a new strain of Ehrlichia canis from South America. 45: 2716-2719.

18. Yu X, McBride JW, Diaz CM, Walker DH. 2000. Molecular cloning and characterization of the 120- kilodalton protein gene of Ehrlichia canis and application of the recombinant 120kilodalton protein for serodiagnosis of canine ehrlichiosis. J Clin Microbiol 38: 369-374. 